\title{
LIGHTNING INJURY IN INDOOR SETTING - A CASE REPORT
}

\author{
BISWAS $\mathrm{S}^{1}$, KARIM ME ${ }^{2}$, CHOWDHURY JA ${ }^{3}$, SARKAR P K ${ }^{4}$, BEGUM M $^{5}$, SARKAR MM ${ }^{6}$, BARDHAN \\ $\mathrm{S}^{7}, \mathrm{DEY} \mathrm{UK}^{8}, \mathrm{BALA} \mathrm{CS}^{9}$
}

\begin{abstract}
:
Lightning strike is a common disaster in Bangladesh. The number of deaths and injuries due to lightning in Bangladesh is over 150 per annum as reported in the newspapers. However, this number may be several times higher as information network in the country is mediocre. The mortality following lightning strike is $10 \%$ to $30 \%$. Most of the casualties occur in an outdoor setting; indoor accidents are much less. A survival case of thunderbolt injury in an indoor setting admitted in Dhaka Medical College, Dhaka, has been reported here.
\end{abstract}

Key words: Lightning Injury.

J Dhaka Med Coll. 2015; 24(1) : 79-81.

\section{Case report:}

A 45 year old lady was admitted inDhaka Medical College Hospital, Dhaka, with a history of thunderbolt injury and weakness of all four limbs along with headache. According to the statement of the patient and her daughter, she was staying near the window of her house when heavy rainfall with thunderstorm was held at their premises. All on a sudden, a thunderbolt had struck at her house through window and was fallen on her head after a reflection from her side window. She was fallen down with injury at scalp and had lost consciousness. After about two hours she became conscious but experienced headache and vomiting due to deep ulcerated burn injury at her scalp (Fig.-1). She also complained of weakness of all four limbs. She was transferred to a local hospital and was given initial treatment. She was referred to Dhaka Medical College Hospital for better management. On examination, Her GCS was 15/15, BP:110/80, Pulse: 98 bpm, muscle

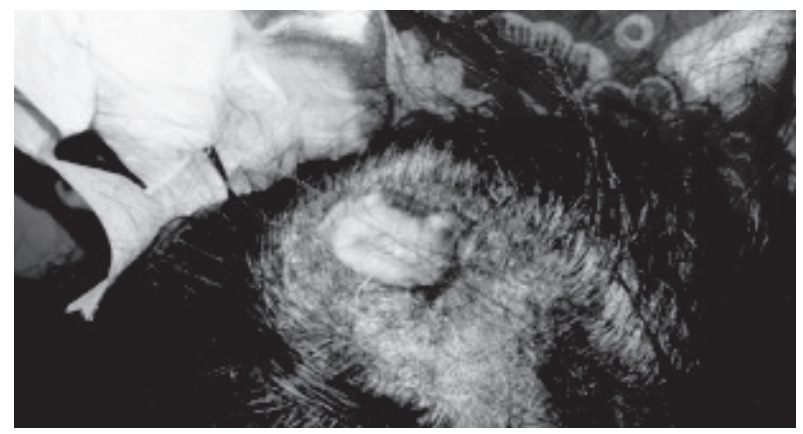

Fig.-1: Deep seated burn injury at scalp.

power was 4/5 in all four limbs with intact reflexes and sensory function. There was a deep seated ulcerated burn injury along the midline over the frontoparietal junction of her scalp measuring $8 \mathrm{~cm} \times 6 \mathrm{~cm}$, surface was lacerated with some sloughs and edge was sloping; it was associated with hair loss of the surrounding area. Other systemic examination revealed normal. ECG showed widespred T wave inversion (Fig. 2).CPK was slightly raised (198

1. Dr. Sarmistha Biswas, Assistant Professor, Department of Medicine, Dhaka Medical College, Dhaka.

2. Dr. Md. Enamul Karim, Professor, Department of Medicine, Dhaka Medical College, Dhaka.

3. Dr. Joybaer Anam Chowdhury, Assistant Registrar, Department of Medicine, Dhaka Medical College Hospital, Dhaka.

4. Dr. Prodip Kumar Sarkar, Indoor Medical Officer, Department of Medicine, Dhaka Medical College Hospital, Dhaka.

5. Dr. Mahmuda Begum, Indoor Medical Officer, Department of Medicine, Dhaka Medical College Hospital, Dhaka.

6. Dr. Md. Mahfuze Sarkar, Register, Department of Medicine, Dhaka Medical College Hospital, Dhaka.

7. Dr. Supta Bardhan, Honourary Medical Officer, Department of Medicine, Dhaka Medical College Hospital, Dhaka.

8. Dr. Uttam Kumar Dey, Senior Medical Officer, BIRDEM, Dhaka

9. Dr. Chandra Shekhor Bala, Junior Consultant, Emergency Medicine, NINS, Dhaka 


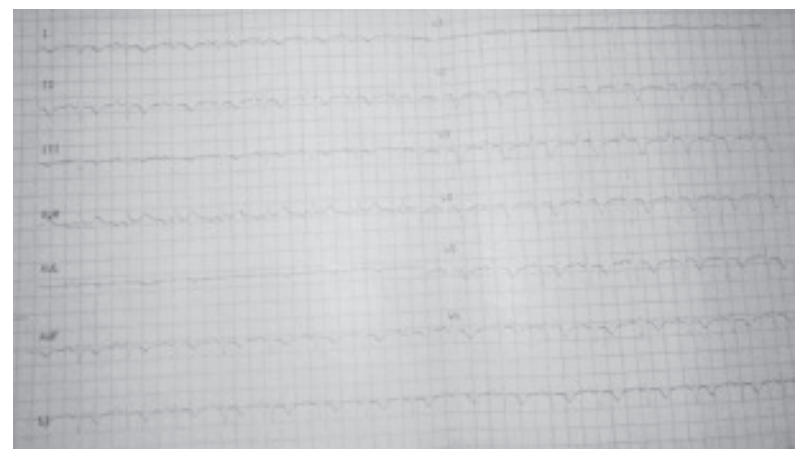

Fig. 2: ECG tracing showing widespread T wave inversion.

U/L). Serum Troponin, Electrolytes, Creatinine,Complete blood count was within normal level. Random blood sugar test,x-ray Chest and x-ray of cervical spine were normal. CT scan of brain with bony window was done and it was normal. She was treated with Intravenous Ringer's lactate saline along with intravenous antibiotics (Ceftrixone and Flucloxacilin), NSAIDS with Tetanus prophylaxis. Surgical debridement and dressing of the deep burn injury of her scalp was done accordingly. She gradually regained strength of all four limbs and was discharged after one week. ECG was repeated on discharge and it became normal (Fig. 3).

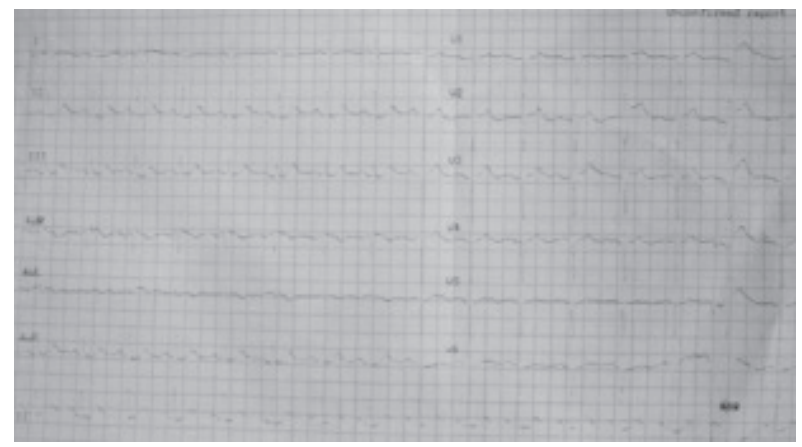

Fig. 3: Normal ECG tracing of the patient during discharge.

\section{Discussion:}

In Bangladesh, the rainfall pattern is influenced by the monsoon winds of the Indian Ocean and the Bay of Bengal. The lightning season is scattered throughout the year but the most vulnerable period is March to June and October to November. ${ }^{1}$ Lightning is a natural atmospheric discharge that occurs between regions of net positive and negative electric charges. This type of injury is common in rural, exposed, outdoor environment than in the cities where high buildings have lightning protection devices. ${ }^{2}$ In a study done by Gomes et $\mathrm{al}^{1}$, it was found that out of total casualties only $30 \%$ are indoor accidents. Out of the indoor lightning injuries almost $75 \%$ is related to the people live in small shelters with metal roofs on brick, clay or wooden walls. Our patient used to live in a brick made house with metal roof. The records of lightning strikes are old as the civilization itself ${ }^{3}$. In ancient timeslightning and thunder strikes were being interpreted as divine punishment, with animistic rituals performed around lightning survivors. ${ }^{4}$ Irrational beliefs surrounded such a natural phenomenon, until Benjamin Franklin discovered in 1752 that lightning itself was electricity. Lightning strike causes human injury by 4 distinct mechanisms: direct, splash, stride, and blast effect. The type of injury depends on energy imparted to the body by the strike that may be mechanical, thermal, or electrical ${ }^{5}$. Lightning injuries may be classified into minor (no loss of consciousness with or without amnesia); moderate (loss of consciousness and subsequent recovery with minor deficit) and severe (full cardiopulmonary arrest) ${ }^{6,} 7$.Our patient may fall into the moderate category. Cardiac arrest is the main cause of death as well as respiratory failure. ${ }^{8}$ Various cardiac abnormalities like dysrhythmias, ST-T wave changes even myocardial infarction due to endothelial damage in coronary arteries may occur in the survival cases. So cardiac monitoring of all patients is needed who have cardiac abnormalities like serial ECG, cardiac enzyme analysis etc. These changes are usually reversible ${ }^{9}$.Location of burn provides a prognostic indicator. Cranial and lower extremity burns have a 4- and 5-fold increase in mortality, respectively, than such burns in any other site ${ }^{10}$. However, irrespective of location, poor wound management leading to infection and gangrene is a further indicator of increase in morbidity and mortality. As lightning is a common natural phenomena in our country, so prompt and proper care of lightning injuries as well as extensive awareness programme should be ensured. 


\section{References:}

1. Gomes C, Ahmed M, Shuvra FH, Abeysinghe KR. Lightning accidents and awareness in South Asian: experience in Sri Lanka and Bangladesh.International Conference on Lightning Protection, Kanazawa, Japan, 2006.

2. Edlich RF, Farinhold HA. Burns, lightning injuries. eMed J 2001; 2:1-16.

3. Conrad L. Clinical update on lightning injuries. Wilderness Environ Med 1998; 9(4):217-22.

4. Tuite K. Lightning, sacrifice, and possession in the traditional religions of the Caucasus. Anthropos 2004; 99: 143-59.
5. Steinbaum S, Harviel JD, Jaffin JH, Jordan MH. Lightning strike to the head: case report. J Trauma 1994;36(1):113-5.

6. Bjarke S, Lintzenich AH. Lightning injuries. eMed J 2004;30: 1-9.

7. Strasser EJ, Davis RM, Menchey MJ. Lightning injuries. J Trauma 1997;17:315.

8. Murty OP, Kian CK, Husin MHA, KumarN, Yusuf WM. Fatal lightning strikes in malaysia. Am J Med Pathol 2009;30: 246-51.

9. Leiria TLL, Pires LM, Kruse ML, LimaGG. Struck by lightning a case of nature induced Pre-excited atrial fibrillation. Circ Arrhythm Electrophysiol 2013;6: 20-1.

10. Cooper MA. Lightning injuries, prognostic signs for death. Ann Emerg Med 1980;9:134. 